Published in Mat. Res. Soc. Symp. Proc. Vol. 722, K1.3.1 (2002).

\title{
GROWTH OF GaN ON POROUS SiC SUBSTRATES BY PLASMA-ASSISTED MOLECULAR BEAM EPITAXY
}

\author{
C. K. Inoki and T. S. Kuan \\ Department of Physics, University at Albany, SUNY, Albany, NY 12222 \\ C. D. Lee, Ashutosh Sagar, and R. M. Feenstra \\ Department of Physics, Carnegie Mellon University, Pittsburgh, PA 15213
}

\begin{abstract}
We have explored the growth of $\mathrm{GaN}$ on porous $\mathrm{SiC}$ substrates by plasma-assisted molecular beam epitaxy. The porous $4 \mathrm{H}$ - and $6 \mathrm{H}-\mathrm{SiC}(0001)$ substrates used in this study contain 10 to $100-\mathrm{nm}$ sized pores and a thin skin layer at the surface. This skin layer was partially removed prior to the growth by H-etching. Transmission electron microscopy (TEM) observations indicate that the epitaxial GaN growth initiates from the surface areas between pores, and the exposed surface pores tend to extend into $\mathrm{GaN}$ as open tubes and trap Ga droplets. Plan-view TEM observations indicate that the GaN layers grown on porous substrates contain fewer dislocations than layers grown on non-porous substrates by roughly a factor of two. The $\mathrm{GaN}$ layers grown on a porous $\mathrm{SiC}$ substrate were also found to be mechanically more relaxed than those grown on non-porous substrates; electron diffraction patterns indicate that the former are free of misfit strain or are even in tension after cooling to room temperature.
\end{abstract}

\section{INTRODUCTION}

Porous $\mathrm{SiC}$ and $\mathrm{GaN}$ has recently been explored as promising substrates to grow epitaxial $\mathrm{SiC}$ or $\mathrm{GaN}$ with reduced dislocation density [1-6]. Such porous materials are produced by anodizing n-type $\mathrm{SiC}$ in hydrofluoric acid (HF) under ultra-violet illumination [7]. Elongated pores with diameters 10 to $30 \mathrm{~nm}$ are typically formed in $4 \mathrm{H}$ and $6 \mathrm{H} \mathrm{SiC}$ depending on the etching conditions (Fig. 1). Preliminary results for $\mathrm{GaN}$ growth on porous $\mathrm{GaN}$ have shown some promise for improved GaN quality [2-4]. It has been speculated that a porous surface may serve as a template for nano-scale lateral epitaxial overgrowth [4], and that a porous substrate layer may be compliant to any lattice and thermal mismatch strains [2-4]. In this work we grew $\mathrm{GaN}$ films on both porous and non-porous $\mathrm{SiC}$ substrate under nominally identical conditions and evaluated the effect of using the porous substrate. Transmission electron microscopy (TEM) and electron diffraction were employed to characterize the dislocation density and the amount of strain relaxation.

The standard growth conditions optimized for growth on non-porous $\mathrm{SiC}$ were used in this study. The porous $\mathrm{SiC}$ substrates contain a thin skin layer about $50 \mathrm{~nm}$ in thickness with few exposed pores at the surface. As shown in a bright-field, cross-sectional TEM image in Fig. 1, the pores start to form a dense network only below this skin layer. For growth on the porous network, this skin layer must be removed prior to the growth. High temperature H-etching was used for this purpose in the present study, although this process was found to significantly enlarge the pores and modify the pore morphology [8]. Reactive ion beam etching may be a better procedure for skin removal [8].

\section{EXPERIMENTAL}

The porous $4 \mathrm{H}$ and $6 \mathrm{H} \mathrm{SiC}$ substrates used in our experiments were purchased from TDI, Inc. The substrate treatment, growth temperatures, and thicknesses of the GaN layers grown are listed in Table 1. Samples C-1 and C-2 are two halves of the same substrate, with the C-2 half being porous. Hydrogen etching was performed at $1700^{\circ} \mathrm{C}$ and $1 \mathrm{~atm}$ pressure for various durations; for sample A, a $10 \mathrm{~min} \mathrm{H}$-etch was performed to completely remove polishing damage 


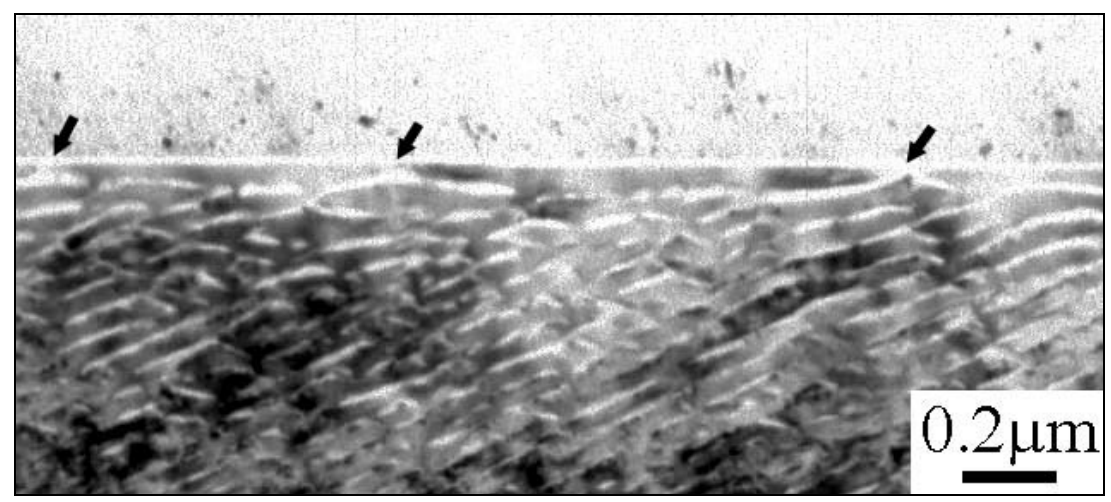

Fig. 1. Cross-sectional TEM image of a porous $6 \mathrm{H}-\mathrm{SiC}$ substrate indicating the presence of a top skin layer. The density of exposed surface pores, as marked by arrows, is very low.

[9] whereas in samples B and C, a brief H-etching was performed in an effort to remove the skin layer above the porous network (although this removal was found to be incomplete, as seen in the TEM images below). The GaN layers were grown by plasma-assisted molecular-beam epitaxy (PAMBE) at $750-800^{\circ} \mathrm{C}$ using a $\mathrm{Ga} / \mathrm{N}$ flux ratios of $1.1-1.5$. The as-grown $\mathrm{GaN}$ samples were examined in a JEOL JEM-200CX transmission electron microscope operating at $200 \mathrm{kV}$.

Table 1 Growth conditions, strain relaxation, and defect density

\begin{tabular}{|c|c|c|c|c|}
\hline Sample & SiC substrate & $\begin{array}{c}\mathrm{T}_{\text {growth, }} \mathrm{Ga} / \mathrm{N} \text { flux ratio, } \\
\mathrm{GaN} \text { thickness }\end{array}$ & Strain relaxation & $\begin{array}{l}\text { Dislocation density } \\
\text { in top layer }\end{array}$ \\
\hline A & $\begin{array}{c}6 \mathrm{H},(0001) \\
\text { H-etched, } 1700^{\circ} \mathrm{C} / 10 \mathrm{~min}\end{array}$ & $\begin{array}{l}800^{\circ} \mathrm{C}, 1.1 \\
1.9 \mu \mathrm{m}\end{array}$ & $\begin{array}{l}\sim 97 \%(\Delta \mathrm{a} / \mathrm{a} \sim 3.4 \%) \\
\mathrm{GaN} \text { in compression }\end{array}$ & $1.1 \times 10^{9} / \mathrm{cm}^{2}$ \\
\hline B & $\begin{array}{l}\text { Porous } 4 \mathrm{H}, 8^{\circ} \text { off }(0001) \\
\text { H-etched, } 1700^{\circ} \mathrm{C} / 1 \mathrm{~min}\end{array}$ & $\begin{array}{c}800^{\circ} \mathrm{C}, 1.1 \\
1.6 \mu \mathrm{m}\end{array}$ & $\sim 100 \%(\Delta \mathrm{a} / \mathrm{a} \sim 3.5 \%)$ & $5.8 \times 10^{8} / \mathrm{cm}^{2}$ \\
\hline $\mathrm{C}-1$ & $\begin{array}{c}6 \mathrm{H}, 3.5^{\circ} \text { off }(0001) \\
\text { H-etched, } 1700^{\circ} \mathrm{C} / 2 \mathrm{~min}\end{array}$ & $\begin{array}{l}750^{\circ} \mathrm{C}, 1.5 \\
0.95 \mu \mathrm{m}\end{array}$ & $\sim 100 \%(\Delta \mathrm{a} / \mathrm{a} \sim 3.5 \%)$ & $5.0 \times 10^{9} / \mathrm{cm}^{2}$ \\
\hline $\mathrm{C}-2$ & $\begin{array}{c}\text { Porous } 6 \mathrm{H}, 3.5^{\circ} \text { off }(0001) \\
\text { H-etched, } 1700^{\circ} \mathrm{C} / 2 \mathrm{~min}\end{array}$ & $\begin{array}{l}750^{\circ} \mathrm{C}, 1.5 \\
0.95 \mu \mathrm{m}\end{array}$ & $\begin{array}{c}\sim 100 \%(\Delta \mathrm{a} / \mathrm{a} \sim 3.7 \%) \\
\mathrm{GaN} \text { in tension }\end{array}$ & $1.9 \times 10^{9} / \mathrm{cm}^{2}$ \\
\hline
\end{tabular}

\section{RESULTS AND DISCUSSION}

\section{A. Growth on non-porous substrates}

Sample A was grown under a Ga-rich condition with a $\mathrm{Ga} / \mathrm{N}$ flux ratio of about 1.1. Under this growth condition, the GaN surface morphology is somewhat facetted, but the defect density is close to minimal as indicated by the x-ray rocking curve measurements [10]. As shown in Fig. 2(a), the threading dislocations tend to interact among each other while propagating upward. Pairs of them combine into a single dislocation or annihilate each other by forming a closed loop, as indicated by arrows in Fig. 2(a). Through these interactions, the dislocation density decreases rapidly as the GaN layer grows thicker. From a plan-view image in Fig. 2(b), we find that the dislocations remain mostly at the valleys (bright and thin areas) of the morphology. This clustering of dislocations by the rough surface topography can enhance their interactions and facilitate the reduction of dislocations [10]. From the plan-view image of Fig. 2(b), we derive that the dislocation density in the top GaN layer of sample A is $1.1 \times 10^{9} / \mathrm{cm}^{2}$ (with a $<6 \%$ error). In the top layer of the sample $\mathrm{C}-1$, which is also grown on a non-porous $6 \mathrm{H}$ substrate, the plan- 
view observation indicates a much higher dislocation density of $5.0 \times 10^{9} / \mathrm{cm}^{2}(<5 \%$ error $)$. This higher density arises because the $\mathrm{Ga} / \mathrm{N}$ flux ratio in that case is larger, about 1.5 , so that the surface morphology is quite flat and the dislocation annihilation by the above mentioned mechanism of clustering near valleys is therefore reduced [10]. (This increase in dislocation density occurs notwithstanding the fact that growth on vicinal substrates, as for sample C-1, generally produces lower dislocation density compared to growth under the same conditions on singular substrates [11]). Also, the GaN layer in sample C-1 is thinner and has undergone fewer dislocation combinations/annihilations than in sample A.

The diffraction pattern in Fig. 2(c) simultaneously records the reflections from the SiC substrate and the GaN overgrown layer. We can, in principle, measure the relative lattice constants of the substrate and the epitaxial film from the pattern. However, one has to be careful in deriving the $\Delta \mathrm{a} / \mathrm{a}$ or $\Delta \mathrm{c} / \mathrm{c}$ values directly from a diffraction pattern, since a slight GaN lattice tilt or rotation relative to the substrate in an Ewald sphere construction will cause a shift in the positions of diffraction spots. Plan-view diffraction patterns obtained in this study indicate that the $\mathrm{GaN}$ c-axis rotation is very small $\left(<0.25^{\circ}\right)$, and the measured $\Delta \mathrm{a} / \mathrm{a}$ values listed in Table 1 should be reliable to about $0.1 \%$. The $\Delta \mathrm{a} / \mathrm{a}$ value for strain-free, bulk $\mathrm{GaN}$ and $\mathrm{SiC}$ is $3.48 \%$ (a: lattice constant of $\mathrm{SiC}$ ). The comparison between the two non-porous growths (sample A and sample C-1) suggests that the off-axis growth gives rise to a more relaxed film.

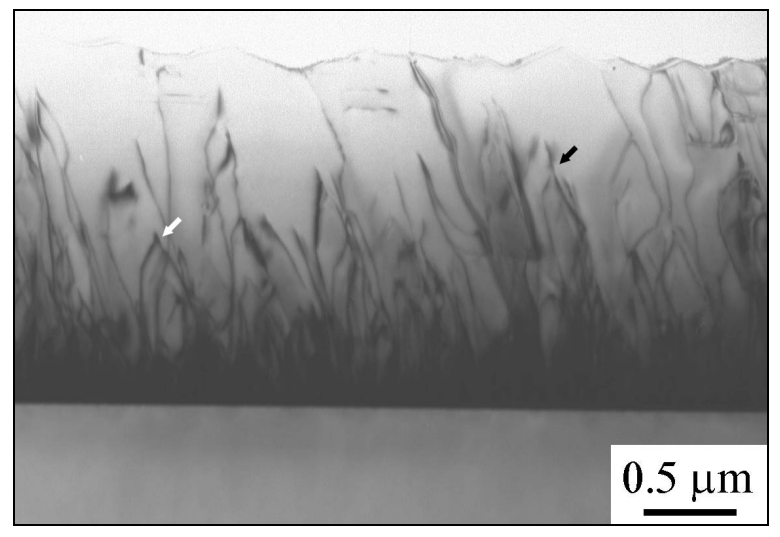

(a)

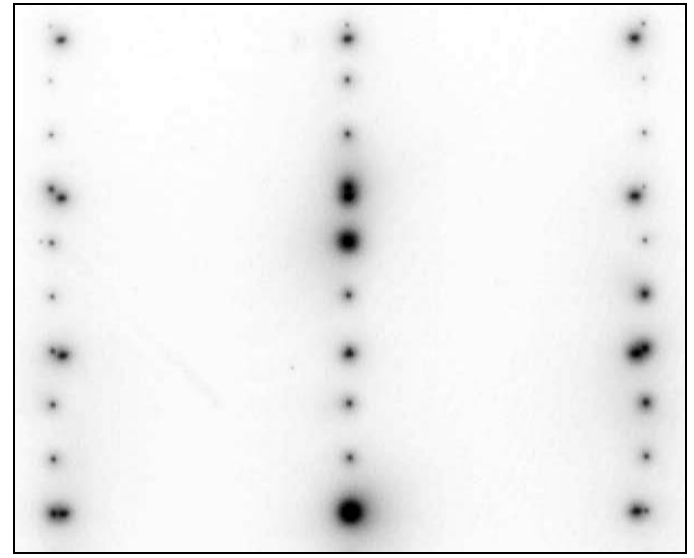

(c)

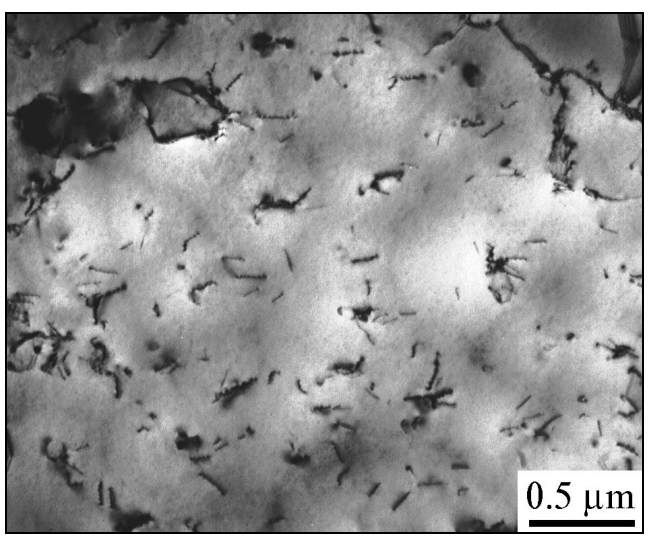

(b)

Fig. 2 (a) Cross-sectional TEM image of a $\mathrm{GaN}$ layer grown on a non-porous $\mathrm{SiC}$ substrate (sample A). Some threading dislocations combine or annihilate each other (marked by arrows) during the growth, resulting in lower defect density in top layers. (b) Plan-view image of the top GaN layer in the sample A. Dislocations tend to cluster toward the valleys of the morphology. (c) Diffraction pattern of sample A. The spacing between the (1010) reflections from $\mathrm{GaN}$ and $\mathrm{SiC}$ indicates a $\Delta \mathrm{a} / \mathrm{a}$ value of about $3.4 \%$.

\section{B. Growth on porous substrates}

At the initial stage of MBE growth of $\mathrm{GaN}$ on a porous $4 \mathrm{H} \mathrm{SiC}$ substrate (sample B), no growth was observed directly on top of an exposed pore [Fig. 3(a)]. The open tube thus formed 
in $\mathrm{GaN}$ can extend to a few hundred nanometers before it is closed. The extension of a GaN tube reflects a low lateral epitaxial growth rate of MBE as compared to the vertical growth rate. Since the growth was carried out under a Ga-rich condition, most of the surface pores and some tubes were filled with Ga. Threading dislocations were observed to emerge from the surface pores as well as from areas in-between pores [Fig. 3(b)]. As in the case of non-porous growth (sample A), dislocation annihilation and combination occurred during growth, resulting in fewer dislocations in the upper part of the film.

Sample C-2, which was grown simultaneously on the porous half of the same $6 \mathrm{H} \mathrm{SiC}$ substrate as sample C-1, shows growth behavior similar to that of sample B. The growth was performed at a lower growth temperature than samples A and B, and we found numerous Ga droplets on the GaN surface [Fig. 4(b)] and more pronounced filling of Ga in surface pores and tubes [Fig. 4(a)]. Nevertheless, Fig. 4(a) reveals dislocation behavior identical to that of samples $\mathrm{A}$ and $\mathrm{B}$ : clustering of dislocations toward recessed surface dimple areas and constant annihilations/combinations of them along the growth. Direct counting of dislocations in planview images such as Fig. 4(b) indicates that the dislocation density in the top layer is lower in sample C-2 than in sample C-1 by about a factor of two $\left(1.9 \times 10^{9} / \mathrm{cm}^{2}\right.$ vs. $\left.5.0 \times 10^{9} / \mathrm{cm}^{2}\right)$. Comparing sample $\mathrm{B}$ (on porous $4 \mathrm{H} \mathrm{SiC}$ ) with sample A (on non-porous $6 \mathrm{H} \mathrm{SiC}$ ), grown under the same conditions, showed similar dislocation reduction.

Besides low defect density, full relaxation of lattice-mismatch and thermal-mismatch induced strains is also important, particularly for large-area growth. As mentioned above, selected area electron diffraction can be used to measure the relative film/substrate lattice constants if the effect of small c-axis tilt and rotation can be ignored. In Fig. 5, we compare the diffraction patterns taken from the nonporous (C-1) and porous growth $(\mathrm{C}-2)$. We find more relaxation, i.e. a larger $\Delta \mathrm{a} / \mathrm{a}$ value, in a film grown on a porous substrate (Table 1). Similarly, sample B is slightly more relaxed than sample A. The $\Delta \mathrm{a} / \mathrm{a}$ of sample $\mathrm{C}-2(3.7 \%)$ exceeds the strain free value of $3.48 \%$ (assuming bulk values for the lattice constants [12]), suggesting that the film is in tension (perhaps because of the additional thermal-mismatch strain introduced during the cooling from the growth temperature to room temperature [13]). We have confirmed the trend of these strain results based on TEM with measurements of wafer curvature using stylus profilometry. We find sample A to have large compression with radius of curvature of $1.2 \mathrm{~m}$ implying a $\Delta \mathrm{a} / \mathrm{a}$ value of $0.10 \%$ less than the strain-free value, whereas samples $\mathrm{B}, \mathrm{C}-1$, and $\mathrm{C}-2$ have relatively little strain $(\mathrm{R}>10 \mathrm{~m})$ and/or are slightly in tension.

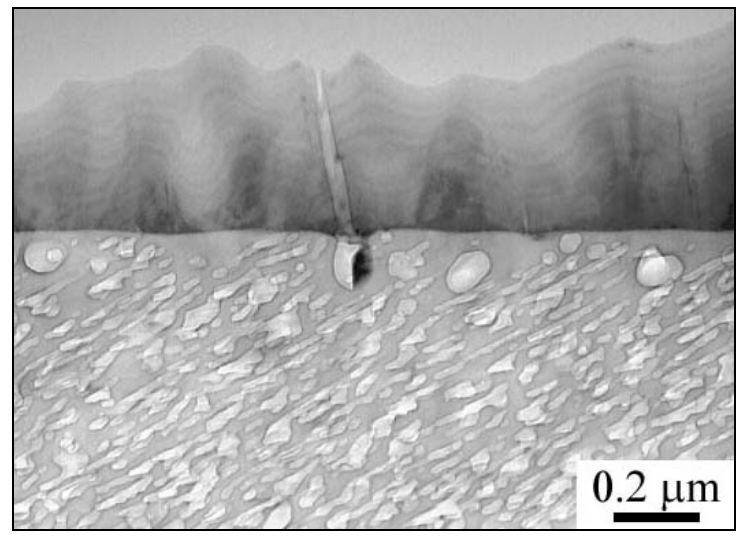

(a)

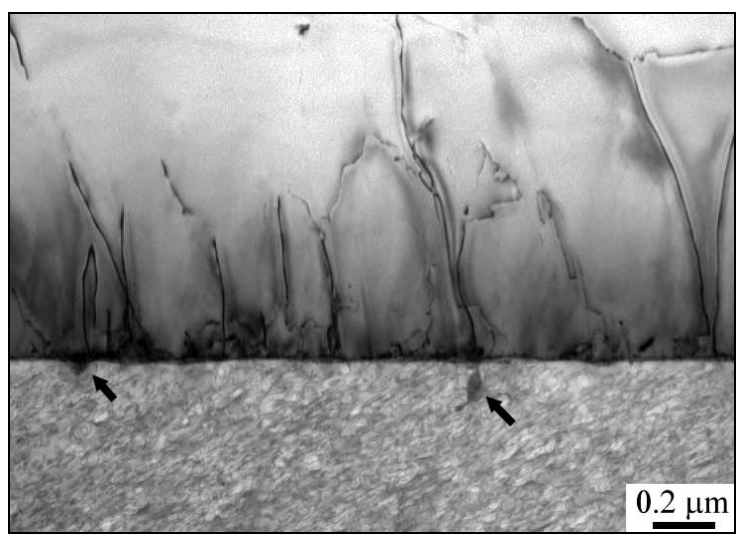

(b)

Fig. 3 (a) A cross-sectional TEM image of sample B showing an exposed pore filled with Ga, and an open tube extended from the pore. (b) Another image of sample B showing dislocations emerging from Ga-filled surface pores (arrows), as well as from areas in-between surface pores. 


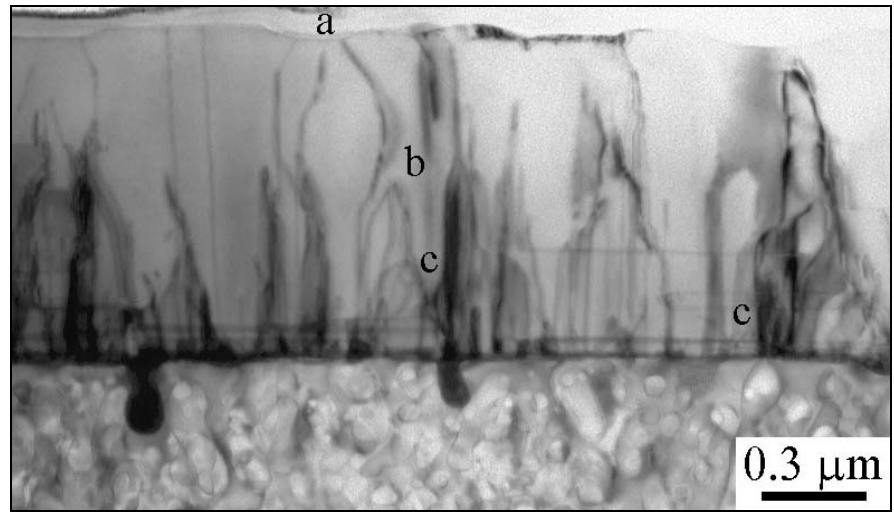

(a)

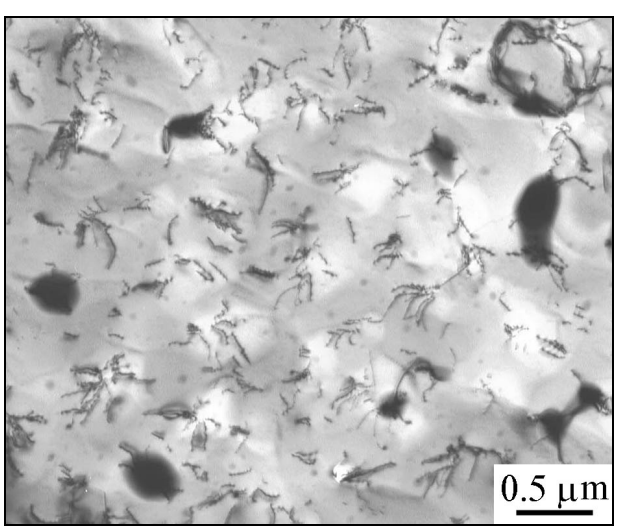

(b)

Fig. 4 (a) A cross-sectional, bright-field image of sample C-2 showing threading dislocations bending toward a surface valley [a] and some of them annihilating each other [b]. Open tubes partially filled with Ga are also observed on top of surface pores [c]. (b) Plan-view micrograph of the top layer of sample $\mathrm{C}-2$, showing the dislocations clustering at surface valleys and the presence of $\mathrm{Ga}$ droplets on the surface.

It is important to note that, although the growths on porous and nonporous substrates were performed under nominally identical conditions, we observe for a fixed heater current during growth that the substrate temperature on the porous wafers is somewhat higher, by about $30-40^{\circ} \mathrm{C}$ for the growth temperatures used here [8]. Some of the differences we find between the growth on porous and nonporous substrates may arise from this factor, since a change in temperature will change the effect $\mathrm{Ga} / \mathrm{N}$ flux ratio, which in turn affects the structural quality of the GaN [10].

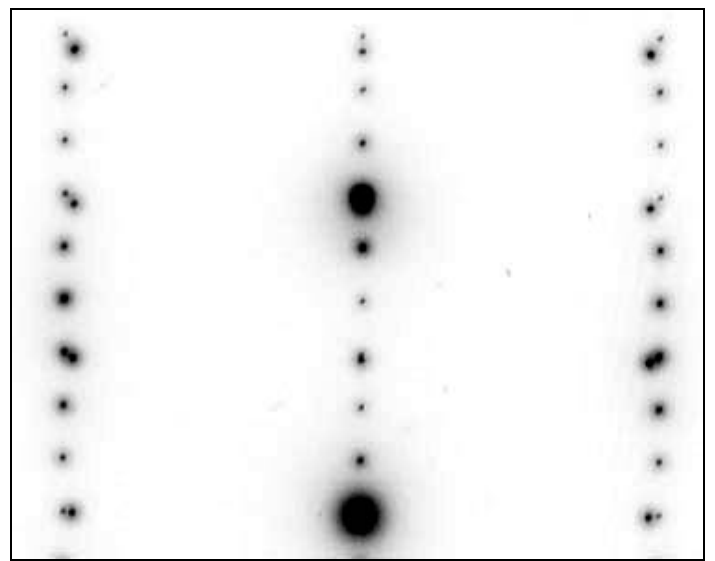

(a)

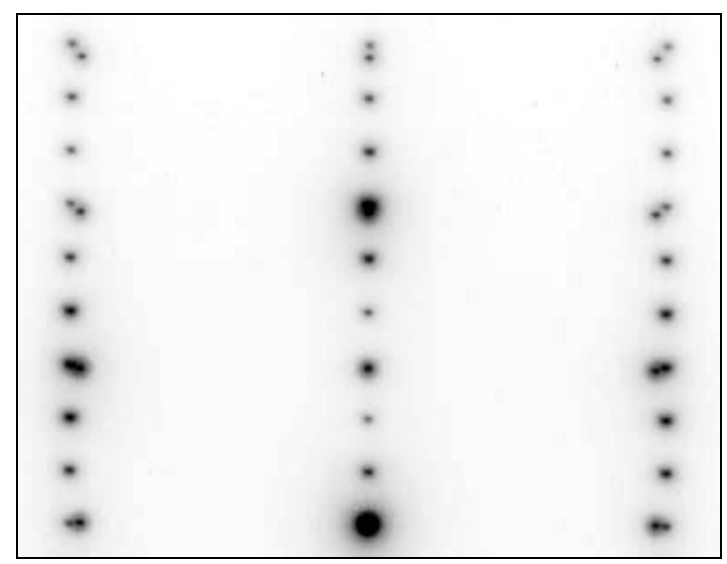

(b)

Fig. 5 Diffraction patterns taken from sample C-1 (a) and from sample C-2 (b).

\section{CONCLUSION}

We have investigated the growth of $\mathrm{GaN}$ on porous $4 \mathrm{H}$ and $6 \mathrm{H} \mathrm{SiC}$ substrates. We have observed reductions of roughly a factor of two in dislocation density in films grown on porous substrates as compared to conventional growth on non-porous $\mathrm{SiC}$ substrates under the same growth conditions. We have also noticed a tendency for growth on porous substrates to produce films that are slightly more relaxed than those of the corresponding non-porous growth. In both porous and non-porous growths, the dislocation density decreases with the GaN layer thickness through a dislocation combination/annihilation mechanism. At the initial stage of growth on 
porous material, because of limited lateral growth, open tubes a few hundred nanometers long are formed on top of the $\mathrm{SiC}$ surface pores. These surface pores and tubes trap Ga droplets under a Ga-rich growth condition or at lower growth temperatures. The mechanisms responsible for the slight reduction in dislocation density and for the increased strain relaxation observed in porous growth are not clear. These two effects might be related. It is possible that the surface pores and the extended tubes can act as convenient dislocation sources to provide misfit dislocation to relax the misfit strain. The open tubes with free surfaces may also serve as sinks to trap threading dislocations.

\section{ACKNOWLEDGMENTS}

This work was supported by a Defense University Research Initiative on Nanotechnology (DURINT) program administered by the Office of Naval Research under Grant N00014-01-10715 (program monitor Dr. Colin Wood).

\section{REFERENCES}

1. S. E. Saddow, M. Mynbaeva, W. J. Choyke, S. Bai, G. Melnychuk, Y. Koshka, V. Dimitriev and C. E. C. Wood, Materials Science Forum 353 -356, 115 (2001) .

2. M. Mynbaeva, A. Titkov, A. Kryzhanovski, V. Ratnikov, H. Huhtinen, R. Laiho and V. Dmitriev, Appl. Phys. Lett. 76, 1113 (2000).

3. M. Mynbaeva, A. Titkov, A. Kryzhanovski, I. Kotousova, A. S. Zubrilov, V. V. Ratnikov, V. Yu. Davydov, N. I. Kuznetsov, K. Mynbaev, D. V. Tsvetkov, S. Stepanov, A. Cherenkov, and V. Dmitriev, MRS Internet J. Nitride Semicond. Res. 4, 14 (1999).

4. M. Mynbaeva, A. Titkov, A. Kryzhanovski, A. Zubrilov, V. Ratnikov, V. Davydov, N. Kuznetsov, K. Mynbaev, S. Stepanov, A. Cherenkov, I. Kotousova, D. Tsvetkov, V. Dmitriev, Mat. Res. Soc. Symp. Vol. 595, W2.7.1 (2000).

5. G. Melnychuk, M. Mynbaeva, S. Rendakova, V. Dmitriev and S. E. Saddow, Mat. Res. Soc. Symp. Vol. 622, T4.2.1 (2000).

6. X. Li, Y. -W. Kim, P. W. Bohn, I. Adesida, Appl. Phys. Lett. 80, 980 (2002).

7. J. S. Shor, I. Grimberg, B. -Z. Weiss and A. D. Kurtz, Appl. Phys. Lett. 62, 2836 (1993).

8. A. Sagar, C. D. Lee, R. M. Feenstra, C. K. Inoki, and T. S. Kuan, submitted to J. Appl. Phys. The increased temperature of porous $\mathrm{SiC}$ is consistent with the well known characteristic of porous Si that its thermal conductivity is 1-2 orders of magnitude lower than that of nonporous Si (see, e.g., S. Perichon et al., Diffus. Defect Data B, Solid State Phenom. 80-81, 417 (2001)).

9. V. Ramachandran, M. F. Brady, A. R. Smith and R. M. Feenstra, J. Electron. Mat. 27, 308 (1998).

10. C. D. Lee, A. Sagar, R. M. Feenstra, C. K. Inoki, T. S. Kuan, W. L. Sarney, and L. Salamanca-Riba, Appl. Phys. Lett. 79, 3428 (2001).

11. C. D. Lee, R. M. Feenstra, O. Shigiltchoff, R. P. Devaty and W. J. Choyke, MRS Internet J. Nitride Semicond. Res. 7, 2 (2002).

12. It is possible that the $\mathrm{SiC}$ lattice constant changes when the material is made porous. For example, porous $\mathrm{Si}$ is found to have a larger lattice constant than nonporous $\mathrm{Si}$ (K. Barla, R. Herino, G. Bomchil, and J. C. Pfister, J. Cryst. Growth 68, 727 (1984)).

13. P. Waltereit, O. Brandt, A. Trampert, M. Ramsteiner, M. Reiche, M. Qi, and K. H. Ploog, Appl. Phys. Lett. 74, 3660 (1999). 